\title{
Inverse Rayleigh Software Reliability Growth Model
}

\author{
B.Vara Prasad Rao \\ Associate Professor of Computer Science, \\ Department of Computer Science \& Engineering, \\ R.V.R \& J.C College of Engineering, Chowdavaram, \\ Guntur- 522 019, Andhra Pradesh, India.
}

\author{
K.Gangadhara Rao \\ Associate Professor of Computer Science, \\ Department of Computer Science \& Engineering, \\ Acharya Nagarjuna University, \\ Guntur- 522 010, Andhra Pradesh, India.
}

\author{
B.Srinivasa Rao \\ Associate Professor of Statistics, \\ Department of Mathematics \& Humanities, \\ R.V.R \& J.C College of Engineering, Chowdavaram, \\ Guntur- 522 019, Andhra Pradesh, India.
}

\begin{abstract}
A Non Homogenous Poisson Process (NHPP) with its mean value function generated by the cumulative distribution function of inverse Rayleigh distribution is considered. It is modeled to assess the failure phenomenon of a developed software. When the failure data is in the form of number of failures in a given interval of time the model parameters are estimated by the maximum likelihood method. The performance of the model using four data sets is discussed in comparison with existing models.
\end{abstract}

\section{General Terms:}

NHPP- non homogenous poisson process

SRGM- software reliability growth model

MLE- maximum likelihood estimation

MSE- mean square error

IRD- inverse Rayleigh distribution

\section{Keywords:}

\section{IRD,MLE,MSE,NHPP,SRGM}

\section{INTRODUCTION}

It is well-known that computers are used in diverse areas for various applications. The growing importance of software dictates that a reliable software is by all means essential. A software itself does not fail unless the faults within the software result in its failure. Generally, software faults are more difficult to handle. All design faults are present from the time the software is installed in the computer. A software fault inherent in a program is not dangerous unless and until it results in a failure of software. Accordingly, the concept of software reliability is rather dependent on the failure of a software and its frequency rather than the unknown number of faults latent in the software. Therefore, the term software reliability may be defined as the probability of failure free functioning of a software rather than the faults contained in it. However we cannot risk out the fact that software reliability depends on the number of faults also. In this regard, theory of probability and hence statistical analysis have become essential in the development of a model that can be used to evaluate the reliability of real world software systems. Quantifying the software quality in terms of reliability is attempted through the study of software reliability growth models.Software reliability models are statistical models which can be used to make predictions about a software system's failure rate, given the failure history of the system. The models make assumptions about a fault discovery and removal process. These assumptions determine the form of the model and the meaning of the model's parameters. Some recent works in this regard are by Akaike(1974) [1], Yamada et al(1986) [15], Huang et al(1999) [10], Pham et al(1999) [13], Huang et al(2000) [11], Kapur et al(2002) [3], Haung and Kuo(2002) [6], Pham and Zhang(2003) [18], Yamada et al(2003) [20], Yamada and Inoue(2004) [22], Huang(2005) [7], Huang and Lyu(2005) [8], Kapur et al(2005) [2], Pham(2005) [5], Quadri et al(2006) [16], Huang et al(2007) [23], Lan and Leemis(2007) [12]. With this backdrop, we study the modeling of software reliability as a Non Homogenous Poisson Process (NHPP) with mean value function based on inverse Rayleigh distribution. Similar attempts based on Pareto distribution is made by Kantam and Subbarao(2009) [9] and that based on half logistic distribution is given by Srinivasa Rao et al(2011) [19]. The genesis and the development of the model with the necessary input about a Non Homogenous Poisson Process are presented in Section 2. Maximum likelihood (ML) estimation of the parameters of the developed software reliability growth model (SRGM) is discussed in Section 3. The proposed SRGM is then compared with other software reliability growth models in Section 4 . The concept of cost aspect in developing a software, associated randomness and the optimum release time of a developed software with respect to cost aspect are given in Section 5. Summary and Conclusions are given in Section 6.

\section{SRGM AS A NON HOMOGENOUS POISSON PROCESS}

Suppose that we are interested in observing the occurrences of a repeatable event over a period of time. The situation relevant here can be the number of times a developed software fails in a given period of testing/operational time. As failures do not occur in a predictable way such a failure process can be identified with a random counting process, generally defined as a count of number 
of events that have occurred in a specified interval of time. Let it be denoted by $N(t)$, where $t$ is any non negative real number. $N(t)$ indicates the number of random occurrences in the interval $[0, t]$. A counting process is said to be a Poisson process if the failure has stationary independent increments and the number of failures in any time interval of length $s$ has a Poisson distribution with mean $\lambda s$ given by

$$
\mathrm{P}(\mathrm{N}(\mathrm{t}+\mathrm{s})-\mathrm{N}(\mathrm{t})=\mathrm{y})=\frac{\mathrm{e}^{-\lambda \mathrm{s}}(\lambda \mathrm{s})^{\mathrm{y}}}{\mathrm{y} !}, \mathrm{y}=0,1,2, \ldots
$$

This mathematical model indicates that the changes in $N(t)$ from one time period to another time period say $[t, t+s]$ depend only on the length of the interval $s$ but not on the extremities $t, t+s$ of the interval. $\lambda$ is called the failure intensity. In the above equation $E[N(t)]=\lambda t, \forall t$. If we think of a Poisson process whose mean depends on the starting $t$ and also the length of the interval $s$ such a Poisson process can be explained by an equation as

$$
\mathrm{P}(\mathrm{N}(\mathrm{t})=\mathrm{y})=\frac{\mathrm{e}^{-\mathrm{m}(\mathrm{t})}(\mathrm{m}(\mathrm{t}))^{\mathrm{y}}}{\mathrm{y} !}, \mathrm{y}=0,1,2, \ldots
$$

In this equation $m(t)$ is a positive valued, non decreasing, continuous function of $t$, generally tending to a finite limit 'a' as $t \rightarrow$ $\infty . m(t)$ is called the mean value function and its derivative with respect to $t$ is the intensity function $\lambda(t)$. Equation (2) is called a Non Homogenous Poisson Process. If a software system when put to use fails with probability $F(t)$ before time $t$, if 'a' stands for the unknown eventual number of failures that it is likely to experience, then the average number of failures expected to be experienced before time $t$ is $a F(t)$. Hence $a F(t)$ can be taken as the mean value function of an NHPP. In the theory of probability, $F(t)$ is called the cumulative distribution function (CDF) of a continuous non negative valued random variable. Thus an NHPP designed to study the failure process of a software can be constructed as a Poisson process with mean value function based on the cumulative distribution function of a continuous positive valued random variable. Since a number of distributions is available in statistical science, one can think of a number of NHPP models each based on a CDF. The first and foremost of such models is due to Goel and Okumoto(1979) [4] which is based on the well-known exponential distribution. Later many such models have been suggested and studied by various researchers that can be found in Wood(1996) [21], Pham(2000) [17] and Huang et al (2007) [23] and references therein. The probability density function (pdf)of inverse Rayleigh distribution (IRD)with scale parameter $\mathrm{b}$ is

$$
f(x)=\frac{2 b}{x^{3}} e^{\left(-\frac{b}{x^{2}}\right)}, \quad x>0, b>0
$$

Its cumulative distribution function (cdf) is given by

$$
F(x)=e^{\left(-\frac{b}{x^{2}}\right)}, \quad x>0, b>0
$$

We consider an NHPP with the mean value function given in terms of the CDF of inverse Rayleigh distribution(IRD) given as

$$
\mathrm{m}(\mathrm{t})=\mathrm{e}^{\frac{-\mathrm{b}}{\mathrm{t}^{2}}} \times \mathrm{a} \quad \mathrm{a}>0, \mathrm{t}>0
$$

It can be seen that $m(t)$ tends to 'a' as $t \rightarrow \infty$ and $m(t)$ is a positive valued non decreasing function of $t$.

The reliability in the software system with the above modeling is the probability of no failures in the time interval $[0, t]$ and is given by

$$
\mathrm{R}(\mathrm{t})=\mathrm{P}\{\mathrm{N}(\mathrm{t})=0\}=\mathrm{e}^{-\mathrm{m}(\mathrm{t})}
$$

In general, the reliability $R(x / t)$ the probability that there are no failures in the interval $[t, t+x]$ is given by

$$
\mathrm{R}(\mathrm{x} / \mathrm{t})=\mathrm{P}\{\mathrm{N}(\mathrm{t}+\mathrm{x})-\mathrm{N}(\mathrm{t})=0\}=\mathrm{e}^{-[\mathrm{m}(\mathrm{t}+\mathrm{x})-\mathrm{m}(\mathrm{t})]}
$$

Generally, the expression given in Equation (7) is called software reliability based on NHPP and this is also called as software reliability growth model (SRGM). If the mean value function is completely specified with its parameters we can have the value of the software reliability at any time of our choice. If the parameters of the mean value function are not known they need to be estimated by a software failure data in the form of failure counts which can be used to get an estimate of the software reliability in order to assess the software quality. We present the ML estimation of parameters in an NHPP based on inverse Rayleigh distribution in section 3 .

\section{ML ESTIMATION}

Suppose that software failure data are given in the form of $\left(y_{i}, t_{i}\right) \mathrm{i}=1,2, \ldots \mathrm{n}$ where $y_{i}$ is the number of failures observed in the interval $\left[0, t_{i}\right] \mathrm{i}=1,2, \ldots \mathrm{n}$ with $0<t_{1}<t_{2}<\ldots<t_{n}$. Such a data is called failure count data. The log likelihood function to get the estimates of parameters of the NHPP shall be of the form

$$
\begin{gathered}
\mathrm{LLF}=\sum_{\mathrm{i}=1}^{\mathrm{n}}\left(\mathrm{y}_{\mathrm{i}}-\mathrm{y}_{\mathrm{i}-1}\right) \log \left[\mathrm{m}\left(\mathrm{t}_{\mathrm{i}}\right)-\mathrm{m}\left(\mathrm{t}_{\mathrm{i}-1}\right)\right]-\mathrm{m}\left(\mathrm{t}_{\mathrm{n}}\right) \\
\frac{\partial}{\partial \mathrm{a}}(\mathrm{LLF})=0, \Rightarrow \mathrm{a}=\mathrm{y}_{\mathrm{n}} \times \mathrm{e}^{\frac{\mathrm{b}}{\mathrm{t}_{\mathrm{n}}^{2}}} \\
\frac{\partial}{\partial \mathrm{b}}(\mathrm{LLF})=0, \Rightarrow \sum_{\mathrm{i}=1}^{\mathrm{n}} \frac{\mathrm{t}_{\mathrm{i}-1}^{2} \mathrm{e}^{\frac{-\mathrm{b}}{\mathrm{t}_{\mathrm{i}-1}^{2}}}-\mathrm{t}_{\mathrm{i}}^{2} \mathrm{e}^{\frac{-\mathrm{b}}{\mathrm{t}_{\mathrm{i}}^{2}}}}{\mathrm{e}^{\frac{-\mathrm{b}}{\mathrm{t}_{\mathrm{i}}^{2}}}-\mathrm{e}^{\frac{-\mathrm{b}}{\mathrm{t}_{\mathrm{i}-1}^{2}}}}\left(\mathrm{y}_{\mathrm{i}}-\mathrm{y}_{\mathrm{i}-1}\right)-\mathrm{y}_{\mathrm{n}} \mathrm{t}_{\mathrm{n}}^{2}=0
\end{gathered}
$$

Solving the equations (9) and (10) simultaneously for a given sample data we get the ML estimates of a and $b$. However, these two equations admit only iterative solutions. The ML estimates for four different data sets published in Wood(1996) [21] given in Table 3.1 using the equations (9) and (10) are given in the first part of Table 4.1. 


\begin{tabular}{|c|c|c|c|c|c|c|c|c|}
\hline \multicolumn{9}{|c|}{ Table 3.1} \\
\hline & \multicolumn{2}{|c|}{ Data Set 1} & \multicolumn{2}{|c|}{ Data Set 2} & \multicolumn{2}{|c|}{ Data Set 3} & \multicolumn{2}{|c|}{ Data Set 4} \\
\hline $\begin{array}{c}\text { Test } \\
\text { Week }\end{array}$ & $\begin{array}{l}\text { CPU } \\
\text { hours }\end{array}$ & $\begin{array}{l}\text { defects } \\
\text { found }\end{array}$ & $\begin{array}{l}\text { CPU } \\
\text { hours }\end{array}$ & $\begin{array}{l}\text { defects } \\
\text { found }\end{array}$ & $\begin{array}{l}\mathrm{CPU} \\
\text { hours }\end{array}$ & $\begin{array}{l}\text { defects } \\
\text { found }\end{array}$ & $\begin{array}{l}\text { CPU } \\
\text { hours }\end{array}$ & $\begin{array}{l}\text { defects } \\
\text { found }\end{array}$ \\
\hline 1 & 519 & 16 & 384 & 13 & 162 & 6 & 254 & 1 \\
\hline 2 & 968 & 24 & 1186 & 18 & 499 & 9 & 788 & 3 \\
\hline 3 & 1,430 & 27 & 1471 & 26 & 715 & 13 & 1054 & 8 \\
\hline 4 & 1,893 & 33 & 2236 & 34 & 1137 & 20 & 1393 & 9 \\
\hline 5 & 2,490 & 41 & 2772 & 40 & 1799 & 28 & 2216 & 11 \\
\hline 6 & 3,058 & 49 & 2967 & 48 & 2438 & 40 & 2880 & 16 \\
\hline 7 & 3,625 & 54 & 3812 & 61 & 2818 & 48 & 3593 & 19 \\
\hline 8 & 4,422 & 58 & 4880 & 75 & 3574 & 54 & 4281 & 25 \\
\hline 9 & 5,218 & 69 & 6104 & 84 & 4234 & 57 & 5180 & 27 \\
\hline 10 & 5,823 & 75 & 6634 & 89 & 4680 & 59 & 6003 & 29 \\
\hline 11 & 6,539 & 81 & 7229 & 95 & 4955 & 60 & 7621 & 32 \\
\hline 12 & 7,083 & 86 & 8072 & 100 & 5053 & 61 & 8783 & 32 \\
\hline 13 & 7,487 & 90 & 8484 & 104 & - & - & 9604 & 36 \\
\hline 14 & 7,846 & 93 & 8847 & 110 & - & - & 10064 & 38 \\
\hline 15 & 8,205 & 96 & 9253 & 112 & - & - & 10560 & 39 \\
\hline 16 & 8,564 & 98 & 9712 & 114 & - & - & 11008 & 39 \\
\hline 17 & 8,923 & 99 & 10083 & 117 & - & - & 11237 & 41 \\
\hline 18 & 9,282 & 100 & 10174 & 118 & 一 & - & 11243 & 42 \\
\hline 19 & 9,641 & 100 & 10272 & 120 & 一 & 一 & 11305 & 42 \\
\hline 20 & 10,000 & 100 & - & - & - & - & - & - \\
\hline
\end{tabular}

\section{COMPARATIVE STUDY}

The present SRGM based on NHPP model can be compared with other models also w.r.t some criteria of preference. The standard models that are considered here are those based on the

(i) Exponential cumulative distribution function.

(ii) Half logistic cumulative distribution function.

(iii) Gamma cumulative distribution function with shape parameter 2 .

in succession. The first NHPP is called Goel -Okumoto model (1979) [4]. The second NHPP is software reliability growth model based on half logistic model(2011) [19]. The third NHPP is called Yamada S-shaped software reliability growth model (1983) [14]. For a ready reference,given below are the mean value functions and associated results of differentiation useful to get the ML estimates of the parameters in our proposed model and the three competitive models.

(1) Inverse Rayleigh Distribution(The proposed model):

$$
\begin{aligned}
& \sum_{i=1}^{n} \frac{t_{i-1}^{2} \frac{e^{\frac{-b}{t_{i-1}^{2}}}-t_{i}^{2} e^{\frac{-b}{t_{i}^{2}}}}{e^{\frac{-b}{t_{i}^{2}}}-e^{\frac{-b}{t_{i-1}^{2}}}}\left(y_{i}-y_{i-1}\right)+y_{n} t_{n}^{2}=0}{a=y_{n} \times e^{\frac{b}{t_{n}^{2}}}}
\end{aligned}
$$

(2) Exponential Distribution(Goel-Okumoto(1979) [4] Model):

$$
\begin{aligned}
& \left.\sum_{i=1}^{n} \frac{t_{i} e^{-b t_{i}}-t_{i-1} e^{-b t_{i-1}}}{e^{-b t_{i-1}-e^{-b t_{i}}}\left(y_{i}\right.}-y_{i-1}\right)-\frac{y_{n} t_{n} e^{-b t_{n}}}{1-e^{-b t_{n}}}=0 \\
& \mathrm{a}=\frac{\mathrm{yn}_{\mathrm{n}}}{1-\mathrm{e}^{-\mathrm{bt}_{\mathrm{n}}}}
\end{aligned}
$$

(3) Half Logistic Distribution:

$$
\begin{aligned}
& \sum_{i=1}^{n} \frac{\frac{t_{i} e^{-b t_{i}}}{\left(1+e^{\left.-b t_{i}\right)^{2}}-\frac{t_{i-1} e^{-b t_{i-1}}}{\left(1+e^{-b t_{i}-1}\right)^{2}}\right.}}{\hat{a}\left[\frac{-2 e^{-b t_{i}}}{\left(1+e^{-b t_{i}}\right)\left(1-e^{\left.-b t_{i-1}\right)}\right.}\right]}\left(y_{i}-y_{i-1}\right)-\frac{t_{n} e^{-b t_{n}}}{\left(1+e^{-b t_{n}}\right)^{2}}=0 \\
& \mathrm{a}=\mathrm{y}_{\mathrm{n}} \times \frac{1+\mathrm{e}^{-\mathrm{bt}} \mathrm{n}}{1-\mathrm{e}^{-\mathrm{bt}} \mathrm{n}}
\end{aligned}
$$

(4) Gamma Distribution (Yamada(1983) [14] Model):

$$
\begin{aligned}
& \sum_{i=1}^{n} \frac{t_{i}^{2} e^{-b t_{i}-t_{i-1}^{2}} e^{-b t_{i-1}}}{\hat{a}\left[\left(1+b t_{i-1}\right) e^{-b t_{i-1}-\left(1-b t_{i}\right) e^{\left.-b t_{i}\right]}}\left(y_{i}-y_{i-1}\right)-a t_{n}^{2} e^{-b t_{n}}=0\right.} \\
& y_{n}=a\left[1-\left(1+b t_{n}\right) e^{-b t_{n}}\right]
\end{aligned}
$$

Now, we adopt calculation of mean square error(MSE)

\begin{tabular}{|c|c|c|c|}
\hline \multicolumn{4}{|c|}{$\begin{array}{c}\text { Table } 4.1 \\
\text { Estimated values of parameters and MSE }\end{array}$} \\
\hline & \multicolumn{3}{|c|}{ Inverse Rayleigh distribution } \\
\hline & $\mathrm{a}$ & $\mathrm{b}$ & MSE \\
\hline DS 1 & 107.0339 & 27.1805 & 102.4486 \\
\hline DS 2 & 156.6663 & 96.2521 & 700.3687 \\
\hline DS 3 & 68.21619 & 16.1002 & 20.2086 \\
\hline \multirow[t]{3}{*}{ DS 4} & 47.7392 & 46.2382 & 8.4156 \\
\hline & \multicolumn{3}{|c|}{ Exponential distribution } \\
\hline & $\mathrm{a}$ & $\mathrm{b}$ & MSE \\
\hline DS 1 & 104.4582 & 0.1577 & 91.5324 \\
\hline DS 2 & 122.8602 & 0.1979 & 208.8905 \\
\hline DS 3 & 61.1117 & 0.5253 & 504.8928 \\
\hline \multirow[t]{3}{*}{ DS 4} & 43.7504 & 0.1694 & 157.2457 \\
\hline & \multicolumn{3}{|c|}{ Half Logistic distribution } \\
\hline & $\mathrm{a}$ & $\mathrm{b}$ & MSE \\
\hline DS 1 & 101.8768 & 0.2339 & 71.3439 \\
\hline DS 2 & 122.8363 & 0.2342 & 196.5170 \\
\hline DS 3 & 63.2061 & 0.3358 & 103.4418 \\
\hline \multirow[t]{3}{*}{ DS 4} & 43.0577 & 0.2309 & 42.0143 \\
\hline & \multicolumn{3}{|c|}{ Gamma distribution } \\
\hline & $\mathrm{a}$ & $\mathrm{b}$ & MSE \\
\hline DS 1 & 299.6177 & 0.0595 & 914.2080 \\
\hline DS 2 & 126.3762 & 0.2492 & 15.7047 \\
\hline DS 3 & 216.8435 & 0.0872 & 201.9281 \\
\hline DS 4 & 45.8767 & 0.2157 & 1.2239 \\
\hline
\end{tabular}
for model comparison. The formula is defined as

$$
\sum_{i=1}^{n}\left(y_{i}-m\left(t_{i}\right)\right)^{2}
$$

MSE $=\frac{i=1}{n-N}$ where $\hat{m}(t)$ stands for MLE of $m(t)$. For four sets of Wood(1996), the MLE of the parameters and the estimators of the mean value function are computed and thereby the values of MSE for various models. The results are given in the table 4.1.

\section{OPTIMAL RELEASE POLICY}

The cost of developing software leads to considerable expenses in a software system development. The quality of a software system usually depends upon the length of testing time. The more 
the testing time the more reliable the software is. However, the total cost of software development is also expected to increase. On the other hand, if the testing time is too short, though the cost of software development would be reduced we cannot avoid the customer's risk of receiving unreliable software which in turn leads to increase in cost during the operational phase. Testing is an efficient way to remove faults in software products but testing of all possible executable paths in a general program is impractical. To determine when to stop testing or when to release the software to customers keeping the expected total software cost at a minimum subject to warranty and risk is considered as an optimal release policy.

A cost model is essential to define important software cost factors. It should help software developers in scheduling of resources for prompt delivery. Moreover with a reasonably sufficient reliability the model should contribute to decide an appropriate release time of the software. With these objectives several software cost models are suggested (Pham(2000) [17],Chapter 6). In this section a software cost model with risk factor as discussed in Pham(2000) [17] is adapted and the model is presented in the following lines for a ready reference. A software cost generally consists of the following components.

\section{(i) cost to perform testing}

(ii) cost incurred in removing errors during testing phase

(iii) risk cost due to software failure.

Testing cost is denoted by $C_{1} t$, where $t$ is the total test time. $C_{1}$ is software test cost per unit time. If $N(t)$ stands for number of errors detected by time $t$, expected time to remove all these errors is given by

$$
\mathrm{E}\left(\sum_{\mathrm{i}=1}^{\mathrm{N}(\mathrm{t})} \mathrm{Y}_{\mathrm{i}}\right)=\mathrm{E}[\mathrm{N}(\mathrm{t})] \mathrm{E}\left[\mathrm{Y}_{\mathrm{i}}\right]=\mathrm{m}(\mathrm{t}) \mu_{\mathrm{y}}
$$

where $Y_{i}$ is time to remove the $i^{\text {th }}$ error during testing phase, $m(t)$ is expected number of errors detected by time $t, \mu_{y}$ is expected time to remove an error during testing phase also called $E(Y)$. Therefore the expected cost to remove all errors is given by $C_{2} m(t) \mu_{y}$ where $C_{2}$ is cost of removing each error per unit time during testing. The risk cost due to software failure, after releasing the software is

$$
\mathrm{E}(\mathrm{t})=\mathrm{C}_{3}[1-\mathrm{R}(\mathrm{x} / \mathrm{t})]
$$

where $C_{3}$ is cost due to software failure and $R(x / t)$ is survival probability of the software by $x$ units of time given it is tested for $t$ units of time.Therefore the total expected cost of software is given by

$$
\mathrm{E}(\mathrm{t})=\mathrm{C}_{1} \mathrm{t}+\mathrm{C}_{2} \mathrm{~m}(\mathrm{t}) \mu_{\mathrm{y}}+\mathrm{C}_{3}[1-\mathrm{R}(\mathrm{x} / \mathrm{t})]
$$

The value of $t$ that minimizes the expected total cost in Equation (13) is to be calculated. Such an optimal value of $t$ is called optimal release time. In the expression for $m(t)$ in Equation (13) is taken and the mean value function as given by IRD and $t$ has to be solved. The formula for such a $t$ has to be compared with the value of $t$ for a similar NHPP model say Goel \& Okumoto(1979) [4], half logistic model (2011) [19] , Yamada(1983) [14] etc. The expected cost function given in equation(13) will show an increasing trend and falls down at a certain time and then increases from there. The time instant at which the change in the trend is observed is taken as the optimal time at which the testing is to be stopped and the product is ready for release. This methodology of locating optimum release time is explained with the data set given in Table 5.1.

\begin{tabular}{|c|c|}
\hline \multicolumn{2}{|c|}{ Table 5.1 } \\
\multicolumn{2}{|c|}{$\begin{array}{c}\text { Cumulative number of defects } \\
\text { given in Pham(2000) }[\overline{[7]}\end{array}$} \\
\hline Test week & cumulative defects found \\
\hline 1 & 27 \\
2 & 43 \\
3 & 54 \\
4 & 64 \\
5 & 75 \\
6 & 82 \\
7 & 84 \\
8 & 89 \\
9 & 92 \\
10 & 93 \\
11 & 97 \\
12 & 104 \\
13 & 106 \\
14 & 111 \\
15 & 116 \\
16 & 122 \\
17 & 122 \\
18 & 127 \\
19 & 128 \\
20 & 129 \\
21 & 131 \\
22 & 132 \\
23 & 134 \\
24 & 135 \\
25 & 136 \\
& \\
\hline
\end{tabular}

For the above data, the parameteric values of IRD are $a=136.8905$ and $b=13.2174$. After estimating these values, the goodness of fit for 25 observations showed that $\mathrm{R}=0.8057$. For the above data containing count of cumulative failures, let us start at an arbitrary choice of cumulative failures, say, let us note down the time by which 100 cumulative failures are experienced. In the present example it is.. "97 cumulative failures are observed within 11 weeks". From that time onwards using the data on time $t_{i}$, cumulative number of failures $y_{i}$, the estimate of mean value function with the help of MLEs of the parameters which are given in Table 5.2. is calculated. For the sake of explanation let us take the specified costs $C_{1}, C_{2}, C_{3}$ as $C_{1}=25, C_{2}=200, C_{3}=7000$, the choice $\mu_{y}$ be kept at $\mu_{y}=0.1$ (as considered by Pham (2000) [17]). These specifications would help us to get the values of expected total software cost as given by Equation (13). For various times and cumulative failures of the data set, our chosen time is " $11^{\text {th }}$ week onwards". Therefore from 11th week onwards in the data set at each time point $E(t)$ can be calculated. These are given in Table 5.3, which searches for a trend in $E(t)$ from a rise to a fall and a rise after $11^{t h}$ week onwards say 11.5 etc. It shows that $E(t)$ gives the desired trend of rise-fall-rise at 15.5. Therefore, to release the software after $15^{\text {th }}$ week before $16^{\text {th }}$ week based on IRD is suggest. The same data based on Goel-Okumoto model suggest to release after $20^{t h}$ week as worked out in Pham(2000) [17].Based on half logistic model suggest to release after $17^{t h}$ week as worked out in Srinivas et al (2011) [19] This example also indicates that IRD based NHPP suggests an earlier release than Goel-Okumoto and half logistic models at an optimal expected cost. 


\begin{tabular}{|c|c|c|}
\hline \multicolumn{3}{|c|}{ Table 5.2 } \\
Parametric estimates of testing times \\
\hline Test time T & $\hat{a}$ & $\hat{b}$ \\
\hline 11 & 105.7758 & 10.4800 \\
12 & 118.2575 & 18.5001 \\
13 & 118.2696 & 18.5101 \\
14 & 125.9659 & 24.7903 \\
15 & 133.3727 & 31.4005 \\
16 & 143.0224 & 40.6990 \\
17 & 140.4543 & 40.7090 \\
18 & 145.7193 & 44.5484 \\
19 & 144.8155 & 44.5583 \\
20 & 144.2046 & 44.5683 \\
21 & 144.9345 & 44.5784 \\
22 & 144.7382 & 44.5883 \\
23 & 146.4692 & 47.0679 \\
24 & 146.5202 & 47.1679 \\
25 & 146.8135 & 47.8178 \\
\hline
\end{tabular}

\begin{tabular}{|c|c|}
\hline \multicolumn{2}{|c|}{ Table 5.3 } \\
Expected total cost at testing times \\
\hline Test time t & $\mathrm{E}(\mathrm{t})$ \\
\hline 11.5 & 2681.4664 \\
12.5 & 2638.8900 \\
13.5 & 2614.4390 \\
14.5 & 2602.6788 \\
$\mathbf{1 5 . 5 *}$ & $\mathbf{2 5 9 9 . 9 5 5 7}$ \\
16.5 & 2603.7715 \\
17.5 & 2612.3903 \\
18.5 & 2624.5862 \\
19.5 & 2639.4804 \\
20.5 & 2656.4342 \\
21.5 & 2674.9769 \\
22.5 & 2694.7579 \\
23.5 & 2715.5124 \\
24.5 & 2737.0389 \\
\hline
\end{tabular}

\section{CONCLUSIONS}

The well known inverse Rayleigh distribution of the statistical science to develop a SRGM through NHPP is considered. Its suitability and preferability over three reliability growth models is exemplified with the help of four live data sets. The delay in releasing a software product whose failure phenomenon is approximated by our model, can be reduced in comparison with three competitive models Goel-Okumoto(1979) [4], half logistic (2011) [19] and Yamada(1983)[14].

\section{Acknowledgments}

The authors thank the editor and the reviewers for their helpful suggestions,comments and encouragement, which helped in improving the final version of the paper.

\section{REFERENCES}

[1] Akaike.H. A new look at statistical model identification. IEEE Transactions on Automatic Control, 19:716723, 1974.

[2] Anu Gupta. Kapur.P.K and Omphal Singh. On discrete software reliability growth model and categorization of faults. Operational Research Society of India(OPSEARCH), 42(4):340-354, Dec 2005.

[3] Bardhan.A.K. Kapur.P.K. and Shatnawi.O. Why software reliability growth modelling should define errors of different severity. Journal of Indian Statistical Association, 40(2):119-142, 2002.
[4] Goel.A.L. and Okumoto.K. A time dependent error detection rate model for software reliability and other performance measures. IEEE Transactions on Reliability, 28(3):206-211, 1979.

[5] Hoang Pham. A generalized logistic software reliability growth model. Operational Research Society of India(OPSEARCH), 42(4):322-331, Dec 2005.

[6] Huang and Kuo.S.Y. Analysis of incorporating logistic testing effort function into software reliability modeling. IEEE Transactions on Reliability, 51(3):261-270, Sept 2002.

[7] Huang.C.Y. Performance analysis of software reliability growth models with testing-effort and change-point. Journal of Systems and Software, 76(2), May 2005.

[8] Huang.C.Y. and Lyu.M.R. Optimal release time for software systems considering cost,testing-effort and test efficiency. IEEE transactions on Reliability, 54, Dec 2005.

[9] Kantam.R.R.L. and Subba Rao.R. Pareto distribution - a software reliability growth model. International Journal of Performability Engineering, 5(3):275-281, 2009.

[10] Kuo.S.Y. Huang.C.Y. and Lyu.M.R. Optimal software release policy based on cost, reliability and testing efficiency. In Proceedings of 23rd IEEE Annual International, 1999.

[11] Kuo.S.Y. Huang.C.Y. and Lyu.M.R. Effort-index based software reliability growth models and performance assesment. In Proceedings of 24th IEEE Annual International Computer Software and Applications Conference, pages 454-459, 2000.

[12] Lan.Y. and Leemis.L. The logistic exponential survival distribution. Naval Research Logistics, 55(3):252-264, 2007.

[13] Nordmann.L. Pham.H. and Zhang.X. A general imperfect software debugging model with s-shaped fault detection rate. IEEE Transaction on Reliability, (48):169-175, 1999.

[14] Ohba.M. Yamada.S. and Osaki.S. S-shaped reliability growth modeling for software error detection. IEEE Transactions on Reliability, 32(5):475-484, 1983.

[15] Ohtera.H. Yamada.S. and Narihisa.R. Software reliability growth models with testing effort. IEEE Transactions on Reliability, R-35:19-23, 1986.

[16] Peer.M.A. Quadri.S.M.K., Ahmad.N. and Kumar.M. Nonhomogeneous poisson process software reliability growth model with generalized exponential testing effort function. RAU Journal of Research, 16(1-2):159-163, 2006.

[17] Pham.H. Software Reliability. Springer-Verlag, 2000.

[18] Pham.H. and Zhang.X. Non homogeneous poisson process software reliability and cost models with testing coverage. European Journal of Operational Research, (145):443454, 2003.

[19] Srinivasa Rao.B., Vara Prasad Rao.B., Kantam.R.R.L., Software reliability growth model based on half logistic distribution. Journal of Testing and Evalaution, 39(6):1152-1157, 2011.

[20] Tamura.Y. Yamada.S. and Kimura.M. A software reliability growth model for a distributed development environment. Electronic and Communications in Japan, 83(3):1446-1453, 2003.

[21] Wood.A.P. Predicting software reliability. IEEE Computer, 11:69-77, 1996.

[22] Yamada.S. and Inoue.S. Testing coverage dependent software reliability growth modeling. International Journal of Quality, Reliability and Safety Engineering, 11(4):303312, 2004.

[23] Yen.S.K. Huang.C.Y. and Michael.R.Lyu. An assesment of testing effort dependent software reliability growth models. IEEE Transactions on Reliability, 56(2):198-211, 2007. 